\title{
FREQUENCY OF KIDNEY CANCER IN NEPHRECTOMY SPECIMENS IN DIFFERENT HOSPITALS IN DHAKA BANGLADESH - A RETROSPECTIVE STUDY
}

\author{
MOHAMMAD OHIDUZZAMAN KHAN ${ }^{1}$, MOHAMMAD REZAUL KARIM ${ }^{2}$, MOHAMMAD MUKHLESUR \\ RAHMAN $^{3}$, MUHAMMAD MAHMUD ALAM ${ }^{4}$, MD. SAJID HASAN 5
}

\begin{abstract}
Background: Kidney cancer is uniformly lethal once the tumor extends beyond Fascia Gerota. But if diagnosed early surgery provides excellent results with regard to local disease control and prospect for long term disease free survival.

Objective : To assess the frequency of kidney cancer among the submitted kidney tissue for histopathological examination.

Method: This analytical retrospective observational study of 550 histopathological reports of nephrectomy specimen was done in different hospitals and institute in Dhaka city. Histopathology reports from January 2007 to December 2009 were collected and all data are compiled and analysed using SPSS version 16 and appropriate statistical tests were done to make inference.

Results : During the study period, among the 550 histopathological specimen of kidney tissue, RCC was found to be most common type 201(36.5\%), TCC renal pelvis was 41(7.5\%), Wilms tumor 54(9.8\%) and sarcoma 5 (0.9\%) and rest were benign. Among the 201 cases RCC only in 130 cases tumor grade was mentioned, with grade II most common type.

Peak age group of kidney cancer was found to be $4^{\text {th }}$ decade and no cancer was found between 10 to 30 years of age. Wilms tumor became most common child hood renal malignancy with mean age 7 years.

Conclusion: The results of the study shows kidney cancer, the most lethal of the urologic cancer is not a common cancer in our country. The most affected age group is $5^{\text {th }}$ decade younger than western countries. RCC is the most common type found and males are affected almost twice than female. National cancer registry should be opened and proper entry should be ensured.
\end{abstract}

Bangladesh J. Urol. 2018; 21(2): 83-87

Introduction:

Kidney cancer is the most lethal of the urolologic cancer. More than $80 \%$ of kidney cancer arise in the renal

1. Assistant Professor, Dept. of Urology, Faridpur Medical College, Faridpur.

2. Assistant Professor, Dept. of Urology, Patuakhali Medical College, Patuakhali.

3. Assistant Professor, Dept. of Urology, Syed Nazrul Islam Medical College, Kishoregonj.

4. Resident Surgeon, Mugda Medical College \& Hospita, Dhaka

5. Chairman, Dept. of Urology, Bangabandhu Sheikh Mujib Medical University, Dhaka

Correspondence: Dr. Mohammad Ohiduzzaman Khan, Assistant Professor, Dept. of Urology, Faridpur Medical College, Faridpur. Mobile: 01712666910, E-mail: wahiduro@gmail.com

Received: 9 August 2017

Accepted: 05 March 2018 parenchyma with the reminder in the renal pelvis[1]. Nearly all kidney cancer originates in the renal parenchyma in adult are renal cell carcinoma (RCC). Vast majority of renal pelvis cancer are transitional cell carcinoma. Other less common type of kidney cancer include (1) Sarcoma of kidney (2) Squamous cell carcinoma (3) Lymphoma or leukemia (4) Renal carcinoid tumor (5) Wilms tumor (6) Metastatic carcinoma[2].

RCC accounts for $2 \%$ to $3 \%$ of all adult malignant neoplasm, $85 \%$ of all primary malignant renal tumors. In USA Over all 8.9 new cases are diagnosed per 100,000 population per year, with male to female predominance of $3: 2[3,4]$. 
This is primarily a disease of elderly patient with typical presentation in the sixth and seventh decades of life[4].

The prevalence of renal carcinoma may very based on race with $10 \%$ to $20 \%$ higher incidence rates in African American than in men of all other races[5].

The majority of cases of RCC are believed to be sporadic, only $4 \%$ are familial. The incidence of RCC incresed since 1970 by an average of $3 \%$ for white and $4 \%$ for African American[5].

$\mathrm{RCC}$ in childhood is uncommon representating only $2.3 \%$ to $6.6 \%$ of all renal tumor. Mean age at presentation in children is 8 to 9 years. Incidence is similar in boys and girls[6-8].

$\mathrm{RCC}$ in young adult and children have a prediction for locally advanced high grade disease and unfavourable histologic subtypes[8-9].

The only generally accepted environmental risk factor of kidney cancer is tobacco exposure in all forms. Risks increase with cumulative dose or pack years. ${ }^{10-12}$ Number of other potential risk factors including virus, lead compounds, chemicals such as aromatic hydrocarbon.

Kidney cancer is not uncommon in our country though it is generally assumed that the frequency is low in our country in comparison to western world. But unfortunately there is no reliable data on the frequency of the disease yet today. The proposed study is a retrospective observational study in which recorded data on kidney disease (histopathological diagnosis) from renowned hospitals and clinics of Dhaka city will be collected to see the frequency of kidney cancer. Bangladesh is a small country with a vast population of more than 150 millions and the number of aging people is increasing day by day. Kidney cancer is a disease of aging people and it is probable that the number of people with kidney cancer is also increasing day by day. Our country is largely centralized to the capital city Dhaka. Much of the modern treatment facilities including urological treatment are also centralized to Dhaka. So, it can be assumed logically that a major portion of the kidney cancer cases from different corners of the country are diagnosed and managed in Dhaka city. As a result, data from the renowned public and private hospitals and urological centers of Dhaka city will cover majority of the cases of kidney cancer in the country. Thus this study will reflect a major portion of the kidney cancer cases and will help predict the overall frequency and disease pattern of the country.

\section{Materials and Methods}

It was a hospital or institution based retrospective observational study. A data collection sheet was used for the collection of data. The head of the histopathology department of the selected hospitals or institutions of Dhaka city were invited through a written invitation from the Chairmen, Urology Department, BSMMU to participate in this study through providing relevant data. Data was collected from pathology department of the following tertiary level hospitals and institute of Dhaka city: Bangabandhu Sheikh Mujib Medical University (BSMMU), Dhaka Medical College Hospital, Dhaka, Sir Salimullah Medical College \& Mitford Hospital, Dhaka, National Institute of Kidney Diseases and Urology (NIKDU), National Cancer Institute, Dhaka, BIRDEM Hospital, Dhaka, Barakah kidney Hospital and diagnostic centre, Comfort Nursing Home, Dhaka, Lab Aid Hospital, Dhaka, United Hospital, Dhaka from January 2007 to december 2010. Histopathological specimen of kidney tissue at BSMMU and other selected hospitals and institutes of Dhaka city. Data was analyzed using SPSS program.

\section{Results}

Table-I

Distribution of the whole study patients. $(n=550)$

\begin{tabular}{lcc}
\hline & Number & Percentage \\
\hline Carcinoma & 301 & 54.7 \\
Benign & 249 & 45.3 \\
\hline Total & 550 & 100 \\
\hline
\end{tabular}

Table-II

Distribution of the malignant kidney tumors by histological diagnosis. $(n=301)$

\begin{tabular}{lcc}
\hline Histopathological diagnosis & Number & Percentage \\
\hline RCC & 201 & 66.8 \\
TCC & 41 & 7.5 \\
Wilms & 54 & 9.8 \\
Sarcoma & 5 & 0.9 \\
\hline Total & 301 & 100 \\
\hline
\end{tabular}


Frequency of Kidney Cancer in Nephrectomy Specimens In Different Hospitals in Dhaka Bangladesh - A Retrospective Study

Table-III

Distribution of the malignant kidney tumors according to age $(n=301)$

\begin{tabular}{|c|c|c|c|c|c|c|c|c|c|c|}
\hline \multirow[t]{2}{*}{ Age } & \multicolumn{2}{|c|}{ RCC } & \multicolumn{2}{|c|}{ TCC } & \multicolumn{2}{|c|}{ Wilms } & \multicolumn{2}{|c|}{ Sarcoma } & \multicolumn{2}{|c|}{ Total } \\
\hline & No & $\%$ & No & $\%$ & No & $\%$ & No & $\%$ & No & $\%$ \\
\hline $0-10$ & 0 & 0 & 0 & 0 & 54 & 100 & 0 & 0 & 54 & 17.94 \\
\hline $11-20$ & 0 & 0 & 0 & 0 & 0 & 0 & 0 & 0 & 0 & 0 \\
\hline $21-30$ & 0 & 0 & 0 & 0 & 0 & 0 & 0 & 0 & 0 & 0 \\
\hline $31-40$ & 12 & 5.97 & 0 & 0 & 0 & 0 & 0 & 0 & 12 & 3.99 \\
\hline $41-50$ & 74 & 36.82 & 7 & 17.7 & 0 & 0 & 1 & 20 & 82 & 27.24 \\
\hline $51-60$ & 55 & 27.36 & 23 & 56.09 & 0 & 0 & 2 & 40 & 80 & 26.58 \\
\hline $61-70$ & 48 & 23.88 & 11 & 26.82 & 0 & 0 & 2 & 40 & 61 & 20.27 \\
\hline $71-80$ & 12 & 5.97 & 0 & 0 & 0 & 0 & 0 & 00 & 12 & 3.98 \\
\hline Total & 201 & 100 & 41 & 100 & 54 & 100 & 5 & 100 & 301 & 100 \\
\hline
\end{tabular}

Table-IV

Distribution of RCC by tumor grade. $(n=130)$

\begin{tabular}{lcc}
\hline Grade & Number & Percentage \\
\hline Grade I & 20 & 15.38 \\
Grade II & 55 & 42.30 \\
Grade III & 30 & 23.07 \\
Grade IV & 25 & 19.23 \\
\hline Total & 130 & 100.0 \\
\hline
\end{tabular}

Table-V

Comparison of different malignant kidney tumors and other cancers according to age $(n=301)$

\begin{tabular}{lcccc}
\hline Different & \multicolumn{2}{c}{ Age (Years) } & Total & P value \\
\hline malignant tumour & $0-50$ & $51-80$ & & \\
RCC & 90 & 111 & 191 & $<0.05$ \\
Others & 62 & 38 & 110 & \\
TCC & 7 & 34 & 41 & $<0.05$ \\
Others & 145 & 115 & 260 & \\
Wilms & 54 & 0 & 54 & $<0.05$ \\
Others & 98 & 149 & 247 & \\
Sarcoma & 1 & 4 & 5 & 0.169 \\
Others & 151 & 145 & 296 & \\
\hline
\end{tabular}

Table-VI

Comparison of different malignant kidney tumors and other cancers according to sex $(n=301)$

\begin{tabular}{lcccc}
\hline Different & \multicolumn{2}{c}{ Sex } & Total & P value \\
\cline { 2 - 3 } malignant tumour & Male & Female & & \\
\hline RCC & 134 & 67 & 201 & 0.908 \\
Others & 66 & 34 & 100 & \\
TCC & 31 & 10 & 41 & 0.181 \\
Others & 169 & 91 & 260 & \\
Wilms & 33 & 21 & 54 & 0.359 \\
Others & 167 & 80 & 247 & \\
Sarcoma & 2 & 3 & 5 & 0.207 \\
Others & 198 & 98 & 296 & \\
\hline
\end{tabular}

\section{Discussion}

Malignant renal neoplasm are among the rarer but most lethal of the urological cancer,compared with other tumors they rank thirteenth to seventeenth , accounting in a large composite series drawn from European and American source ,for about $2-3 \%$ of all malignant neoplasm[8]. There is however, little information from south asian countries on the incidence of renal malignant neoplasm in particular.

In present series 550 histopathological reports of kidney tissue of 3 years duration (from January 2007 to December 2009) were reviewed, collected from different Hospitals and institution in Dhaka cities. 
Among the histopathological reports 301(54\%) were diagnosed as kidney cancer of different types and remaining 249 (45.3\%) were benign disease of kidney like chronic pyelonephritis, hydronphrosis ect.

Around 208,500 new cases of kidney cancer are are diagnosed in the world each year, the highest rates are recorded in the Northern America and lowest rate in Asian and African region[13].

In the USA 51,190 new cases of kidney cancer are diagnosed in 2007[14]. The most recent estimates of incidence of kidney cancer suggest that there are 63,300 new cases annually in the EU[15]. This indicate a huge burden of the disease in these countries.

Most (85\%) of all primary malignant renal tumors are RCC. TCC renal pelvis and Sarcoma constitute 5\% and $1 \%$ of malignant renal tumors. Wilms' tumor represent $3 \%$ of adult renal malignancy and $5 \%$ of childhood cancer[16].

In the present series among 301 malignant renal tumor only $201(66.8 \%)$ are RCC, $41(7.5 \%)$ of cases are TCC renal pelvis , $54(9.8 \%)$ are Wilms' tumor and only $5(.9 \%)$ are sarcoma. No leukemia, lymphoma, Neuro endocrine tumor or metastatic renal tumor were reported. So it is evident that RCC constitute the most common type, and TCC renal pelvis became the second most common type in adult population. This data is consistent with internationally recognised data.

RCC occurs most commonly in the $5^{\text {th }}$ decade. The peak age of presentation of Wilms tumor is during third year and there is no sex predilection.

In the present series we found Wilms tumor was only malignant neoplasm in the first decade of life. All 54 cases occur between birth and 10 years, the majority being in the first 6 years of life.

RCC and other two varieties of malignant renal neoplasm are tumor of the adults. About $95 \%$ of RCC that is 189 out of 201 are found in person over 40 years and none is found below 30 years and above 80 years. In the present series $88 \%$ of RCC occurred between ages of 40 to 70 years with peak incidence being $5^{\text {th }}$ decade. The age distribution is much the same as that recorded in the literature.

TCC renal pelvis is common in the $5^{\text {th }}$ decade. Out of 5 cases reviewed in this series 4 occurred between $5^{\text {th }}$ and $6^{\text {th }}$ decade none is found below 30 years.

Renal cell carcinoma collected from literature[8] was found to be commoner in male than females.In the present series of 201 cases of RCC, males were 135 and female 66 with a ratio of 2:1 that is consistent with internationally accepted results. This ratio however was not maintained for Wilms' tumor. Among 54 cases male were 29 and female 25, with a ratio $1.2: 1$ So it is assumed that Wilms tumor has got no sex predilection.

In each of other histological type of renal cancer in these series male predominated. So finding from these series, as well as from the literature indicate that males are affected for more than females by renal cancers.

Grading is an important prognostic criteria of RCC. It represents the aggressiveness of tumor. Among 201 cases of RCC grading of only 130 cases was mentioned in the histo pathological report. In the present series

Most common grade at diagnosis were grade II $42.30 \%(55)$ followed by grade III $23.17 \%$ (30) grade IV $19.23 \%(25)$ and grade I $15.28 \%(20)$.So lower grade tumor with relatively good prignosis are common in this series.

\section{Conclusion}

The results of the study shows kidney cancer, the most lethal of the urologic cancer is not a common cancer in our country. The most affected age group is $5^{\text {th }}$ decade younger than western countries. RCC is the most common type found and males are affected almost twice than female. A large scale prospective study involving all the hospitals of the country should be done to find out the actual prevalence of the disease in the country. Although it will require much money and more effort, involvement of different interested agencies can make the job easy. Not only that, search can be done to find out any modifiable risk factor of the disease which can help preventing the disease and national cancer registry should be opened and proper entry should be ensured.

\section{References}

1. Devessa SS, Silverman DT, McLaughhin, J.k.,Brown CC,Connell, RR, Fraumeni JF $\mathrm{Jr}$,Comparison of the descriptive epidemiology of urinary tract cancer.1990;1:1133-1141.

2. Landis $\mathrm{SH}$, Murray $\mathrm{T}$, Bolden $\mathrm{S}$, Wingo PA: Cancer statistics: 1999. CA Cancer J Clin 1999; 49:8-31.

3. Turner KJ, Moore JW, Jones A, et al: Expression of hypoxia-inducible factors in human renal cancer: Relationship to angiogenesis and to the von Hippel-Lindau gene mutation. Cancer Res 2002; 62:2957-2961. 
4. Pantuck AJ, Zisman A, Belldegrun AS: The changing natural history of renal cell carcinoma. J Urol 2001; 166:1611-1623.

5. Chow GK, Myles J, Novick AC, et al: The Cleveland Clinic experience with papillary (chromophil) renal cell carcinoma: Clinical outcome with histopathological correlation. Can J Urol 2001; 8:1223-1228.

6. Castellanos RD, Aron BS, Evans AT: Renal adenocarcinoma in children: Incidence, therapy and prognosis. J Urol 2004; 111:534-537.

7. Chan HSL, Daneman A, Gribbin M, Martin DJ: Renal cell carcinoma in the first two decades of life. Pediatr Radiol 1983; 13:324-328.

8. Freedman AL, Vats TS, Stewart T, et al: Renal cell carcinoma in children: The Detroit experience. $J$ Urol 1996; 155:1708-1710.

9. GLOBOCON 2002, cancer incidence, mortality and prevalence worldwide 2002 .

10. Kantor AF. Current concepts in the epidemiology and etiology of primary renal cell carcinoma. $J$ Urol 2007; 117:415-417.
11. McLaughlin JK, Lindblad $P$, Mellemgaard A, et al. International renal cell cancer study: I. Tobacco use. Int J Cancer 1995; 60:94-198.

12. Moyad MA: Review of potential risk factors for kidney (renal cell) cancer. Semin Urol Oncol 2001; 19:280-293.

13. Hook Lm, Lynch J,Balagi, K.C:Increasing incidence of all stage kidney cancer in the last two decades in the united states: An analysis of surveillance ,Epidemiology and End Results Programme Data .J Urol 2002:167:57.

14. Jemel A et al. cancer statistic,2007, C A Cancer J Chin 2007,57:43

15. Firoozi and Kogan Firoozi F, Kogan BA. Followup and management of recurrent Wilms' tumor. Urol Clin North Am 2003; 30:869-879.

16. Hock LM, Lynch J, Balaji KC: Increasing incidence of all stages of kidney cancer in the last 2 decades in the United States: An analysis of Surveillance, Epidemiology and End Results program data. $J$ Urol 2002; 167:57-60. 